\title{
Evaluation of bearing capacity of reinforced concrete box ribbed arch bridge based on static load test
}

\author{
Mao $\mathrm{He}^{1}$, Xin $\mathrm{Fu}^{2}$ and Shunchao $\mathrm{Chen}^{1 *}$ \\ ${ }^{1}$ College of Civil Engineering, Southwest Forestry University, Kunming, Yunnan, 650224, China \\ ${ }^{2}$ College of Civil Engineering, Southwest Forestry University, Kunming, Yunnan, 650224, China
}

\begin{abstract}
In order to evaluate the stress and working performance of a reinforced concrete box-ribbed arch bridge after completion, the load test of the bridge is carried out. Static load test is to test the stress and displacement of each section of arch rib under the action of partial load and medium load. Through the experiment with the key parts of the stress (strain) and displacement load and other important data, through analysis and study, the comprehensive analysis of the phenomenon of calculation and test, a comprehensive performance evaluation structure and function whether meet the design requirements, to provide technical basis for the safety of the bridge operation, and provide the original material for the bridge maintenance and management in the future.
\end{abstract}

\section{Introduction}

Arch is a kind of structure bearing type with long history and wide application. Under the vertical load [1], the arch is mainly under axial compression, and the reinforced concrete box ribbed arch bridge can be built by making full use of the concrete material with excellent compressive performance.

The arch rib is composed of two or more separate parallel arch ribs and the roadway plate supported by the column and beam set on the arch rib [2]. Because the arch rib reduces the dead weight of arch ring very well, so the constant load internal force of arch rib is small, live load internal force is larger, with the advantages of saving material, reducing the dead weight, reducing the lower amount of engineering, beautiful appearance, so it should be used in large, medium span reinforced concrete structure.

Along with the economic development of the traffic volume increasing, local service performance of highway Bridges is generally faced with higher requirements [3-4], under the condition of market economy, to supervise the quality of bridge not only can't fade, and must be strengthened, the quality issues at stake, must be the quality of the new bridge inspection, to ensure the performance stability of the bridge during service.

\section{Basic information of bridge}

Because of the need to build a power station, the original part of the road is located in the submerged range, due to the need of was built, on the bridge is built, the bridge is 1 to $40 \mathrm{~m}$ rib reinforced concrete box arch bridge, bridge span $45 \mathrm{~m}$, design speed is $20 \mathrm{~km} / \mathrm{h}$, and design load level for highway - grade I, design flood frequency was $1 / 50$, bridge seismic fortification intensity of for IIV, bridge overall width $9.5 \mathrm{~m}$, width $8.5 \mathrm{~m}$, bridge arrangement as follows: $0.5 \mathrm{~m}$ (crash barrier) $++0.5 \mathrm{~m}$, $8.5 \mathrm{~m}$ (driveway) (crash barrier).

Through the finite element analysis software of Midas Civil bridge, the arch ribs were simulated by beam element, and the strain and displacement values of each measured point in each test section of the structure were obtained by applying static load to the model. Then the bearing capacity of the bridge was evaluated by comparative analysis with the measured values after the real bridge was loaded.

\section{Static load test of bridge}

\subsection{Principle of static load test}

Static load test is mainly used to test the strain, displacement, residual strain and residual deformation of each control section measuring point of the upper main structure of the bridge [5], and comprehensively evaluate the performance of the main structure of the bridge. According to the calculation and analysis, it is determined that the static load test of the bridge needs $4 * 450 \mathrm{kN}$ double axle heavy cars, which are loaded at the most unfavorable position of the influence line of internal force on the control section of the main structure, so that the efficiency coefficient of the test load is between 0.85 and 1.05. Figure1 shows axle weight and wheelbase when the test vehicle is fully loaded.

Strain test: strain gauge is decorated in the corresponding test section at the bottom of the main arch ring and its resistance to $120 \Omega$, sensitivity coefficient is

"Corresponding author e-mail: 410106781@qq.com 
2.08 , the distance of $10 \mathrm{~cm}$, use DH3819 wireless static strain test and analysis system to collect data.

Deflection test: a hook is set at the bottom of the arch rib of each control section, and a wire rope is suspended from the hook. A heavy hammer hung from the bottom of the wire. A dial indicator is set below the hammer body, which is restrained by a fixed bracket

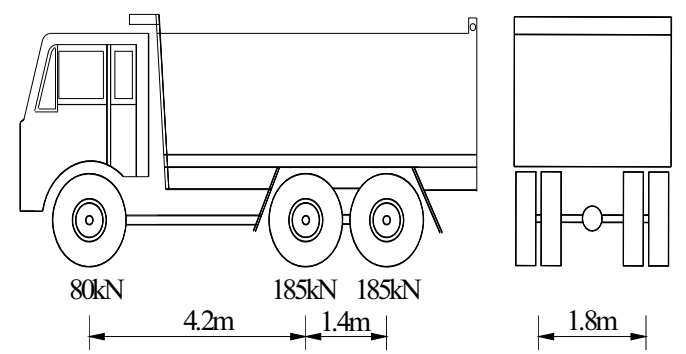

Figure 1. Test vehicle.

\subsection{Test section and measuring point arrangement}

In order to reflect the bearing capacity of the bridge comprehensively, the main arch span of the bridge is taken as the test span. The test sections are 3, namely the $0 \#$ arch foot section JM1, The L/4 section JM2, and the $\mathrm{L} / 2$ section JM3. The specific layout is shown in Figure 2. JM1, JM2 and JM3 strain measuring points were arranged at the top and bottom of the arch rib. Two measuring points were arranged at the top and bottom of the arch rib on both sides of each section, a total of 24 strain measuring points were arranged. The deflection measuring points were arranged on JM2 and JM3 sections. Two measuring points were arranged horizontally for each section, and a total of four measuring points were arranged. The arrangement diagram of strain and deflection measuring points is shown in Figure 3 and 4

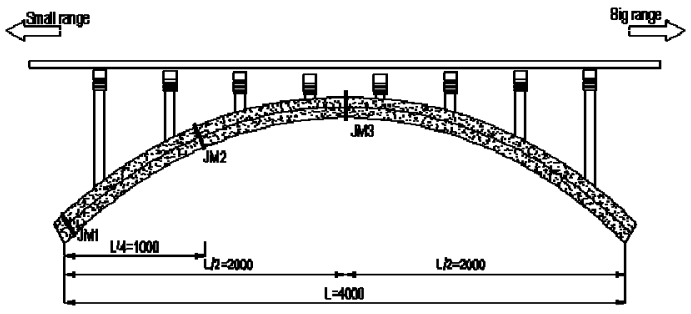

Figure 2. Test section layout (unit: $\mathrm{cm}$ )

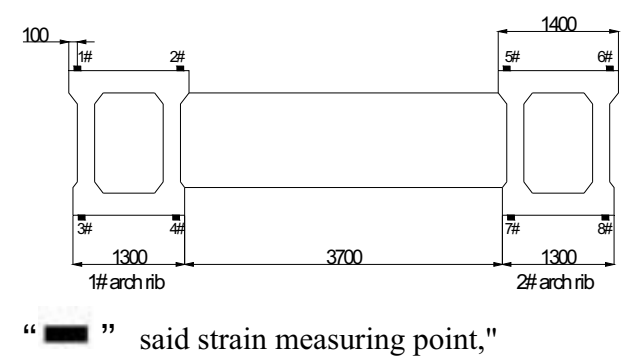

Figure 3. Sectional strain measuring point layout (unit: $\mathrm{cm}$ )

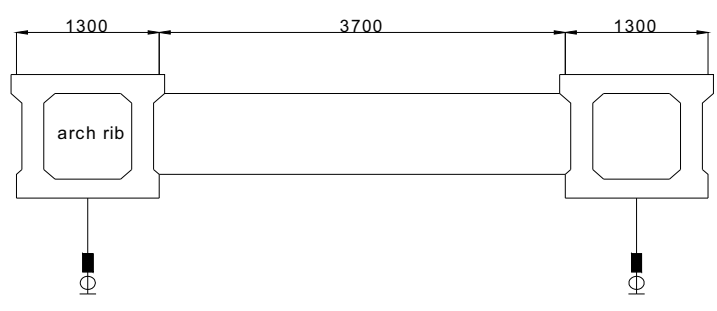

Note: $\Phi$ "said deflection measuring point

Figure 4. Layout of section deflection measurement points (unit: $\mathrm{cm}$ )

\subsection{Load test conditions and load arrangement}

The structure is calculated to be $450 \mathrm{kN}$ loaded at the most unfavorable position in the longitudinal direction of the bridge, and the transverse direction is divided into partial load and medium load. The test content is deflection and strain of the control section under the action of test load. The load test process is shown in Table 1.

Table 1. Load test procedure

\begin{tabular}{|c|c|c|c|c|}
\hline $\begin{array}{l}\text { Load } \\
\text { condition }\end{array}$ & $\begin{array}{c}\text { The control } \\
\text { section }\end{array}$ & Spacing & $\begin{array}{c}\text { Loading } \\
\text { way }\end{array}$ & $\begin{array}{l}\text { The test } \\
\text { content }\end{array}$ \\
\hline \multirow[b]{2}{*}{ Condition 1} & JM1 & \multirow{2}{*}{$\begin{array}{c}\text { Maximum } \\
\text { negative } \\
\text { moment }\end{array}$} & Partial load & \multirow[b]{2}{*}{ Strain } \\
\hline & JM1 & & $\begin{array}{l}\text { Middle } \\
\text { load }\end{array}$ & \\
\hline \multirow[b]{2}{*}{ Condition 2} & JM2 & \multirow{2}{*}{$\begin{array}{l}\text { Maximum } \\
\text { positive } \\
\text { moment }\end{array}$} & Partial load & \multirow{2}{*}{$\begin{array}{l}\text { Deflection } \\
\text { and strain }\end{array}$} \\
\hline & JM2 & & $\begin{array}{c}\text { Middle } \\
\text { load }\end{array}$ & \\
\hline \multirow[b]{2}{*}{ Condition 3} & JM3 & \multirow{2}{*}{$\begin{array}{l}\text { Maximum } \\
\text { positive } \\
\text { moment }\end{array}$} & Partial load & \multirow{2}{*}{$\begin{array}{l}\text { Deflection } \\
\text { and strain }\end{array}$} \\
\hline & JM3 & & $\begin{array}{l}\text { Middle } \\
\text { load }\end{array}$ & \\
\hline
\end{tabular}

\subsection{Static load test efficiency}

In order to meet the requirements of load effect, the number and axle weight of test vehicles are selected according to the principle of control internal force equivalent, which makes the quiet load efficiency $\eta \mathrm{q}$ between 0.85 and 1.05 . The loaded vehicles are weighed before the test. The load efficiency is calculated according to Equation (1) [5] :

$$
\eta_{q}=\frac{S_{s}}{S(1+\mu)}
$$

-Ss -- The maximum calculated effect value of internal force or displacement in the loading control section of a loading test item under static load;

-S -- Calculated value of the most adverse effect of the internal force or displacement in the control section under the same load generated by the control load;

- $\mu$-- Value of impact coefficient as per specification.

In the test load analysis, the 2-lane load was considered, and the impact coefficient was considered in the design load, but the lateral reduction was not considered. The $\mathrm{Q}$ of the static load efficiency is 
between 0.85 and 1.05, which is controlled by adjustment of loading tonnage, loading position and actual situation on site. See Table 2 for the value of the static load efficiency of the bridge.

Table 2. Static load efficiency coefficient

\begin{tabular}{|c|c|c|c|}
\hline Condition & $\mathrm{Ms} /$ (kN.m) & $\mathrm{Mt} /$ (kN.m) & $\eta \mathrm{q}$ \\
\hline Condition1 & -1016.4 & -1033.2 & 0.98 \\
\hline Condition2 & 319.8 & 354.5 & 0.90 \\
\hline Condition3 & 279.6 & 295.0 & 0.95 \\
\hline
\end{tabular}

\section{Analysis of static load test results}

\subsection{Analysis of strain test results.}

Under the load of working conditions $1 \sim 3$, the strain measured value $S_{e}$, calculated value $S_{s}$, residual value $S_{p}$ and relative residual value $S_{p}$ of the measuring point of the test section $1 \sim 8$ are shown in Figure $5 \sim$ Figure 7.

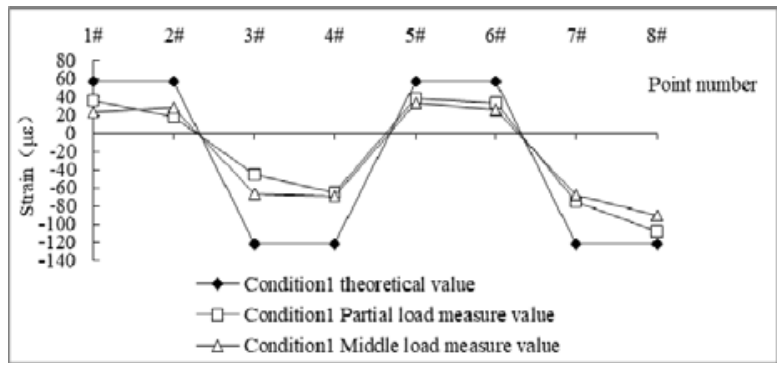

Figure 5. Strain value under working condition 1

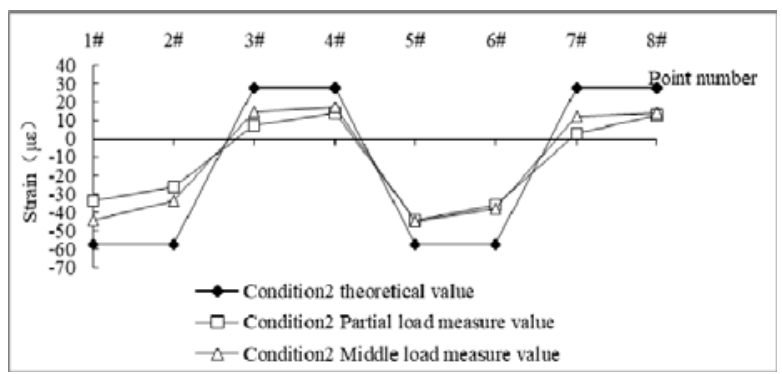

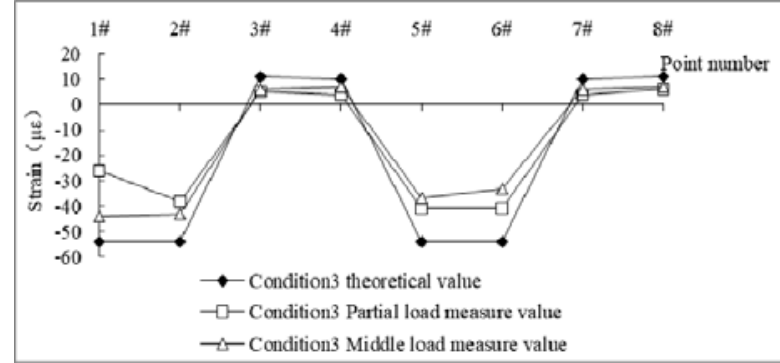

Figure 7. Strain value under working condition 3

It can be seen from the figure above that the test efficiency coefficient of the bridge under various working conditions meets the requirement that the load efficiency coefficient is greater than 0.85 and less than 1.05 , so the test is effective. The measured strain values of the mid-span section of the test bridge are all smaller than the theoretical calculation values, the check coefficient of strain at the main measuring points are all less than 1 , the maximum measured stress increment is less than the limit value of the specification, and the structural strength meets the requirements of the specification. Under the full load in the first and second working conditions, the measured strain value of the mid-span section of the test bridge is similar to the theoretical calculation value, and no obvious abrupt transition point is found, indicating that the lateral transmission force of the superstructure is normal.

\subsection{Analysis of deflection test results}

Under various working conditions, the measured deflection value $\mathrm{f}_{\mathrm{e}}$, theoretical value $\mathrm{f}_{\mathrm{S}}$, total deformation value $f_{t}$, residual value $f_{P}$ and relative residual deformation value $f_{P} / f_{t}$ at the measuring points $1 \sim 4$ are shown in Table 3.

Figure 6. Strain value under working condition 2

Table 3. Comparison between measured deflection and theoretical deflection

\begin{tabular}{|c|c|c|c|c|c|c|c|c|}
\hline $\begin{array}{l}\text { Condi } \\
\text { tion }\end{array}$ & $\begin{array}{c}\text { Loading } \\
\text { way }\end{array}$ & Point & $\mathrm{fe} / \mathrm{mm}$ & $\mathrm{fP} / \mathrm{mm}$ & $\mathrm{ft} / \mathrm{mm}$ & $\mathrm{fs} / \mathrm{mm}$ & $\eta(\mathrm{fe} / \mathrm{fs})$ & $\mathrm{fp} / \mathrm{ft}$ \\
\hline \multirow{4}{*}{$\begin{array}{l}\text { Condi } \\
\text { tion } 2\end{array}$} & \multirow{2}{*}{$\begin{array}{c}\text { Partial } \\
\text { load }\end{array}$} & $1 \#$ & 1.32 & 0.13 & 1.45 & 1.87 & 0.71 & $8.97 \%$ \\
\hline & & $2 \#$ & 2.05 & 0.09 & 2.14 & 2.73 & 0.75 & $4.21 \%$ \\
\hline & \multirow{2}{*}{$\begin{array}{l}\text { Middle } \\
\text { load }\end{array}$} & $1 \#$ & 1.85 & 0.21 & 2.06 & 2.30 & 0.80 & $10.19 \%$ \\
\hline & & $2 \#$ & 1.57 & 0.16 & 1.73 & 2.30 & 0.68 & $9.25 \%$ \\
\hline \multirow{4}{*}{$\begin{array}{l}\text { Condi } \\
\text { tion } 3\end{array}$} & \multirow{2}{*}{$\begin{array}{c}\text { Partial } \\
\text { load }\end{array}$} & $3 \#$ & 1.18 & 0.11 & 1.29 & 1.29 & 0.91 & $8.53 \%$ \\
\hline & & $4 \#$ & 3.95 & 0.34 & 4.29 & 4.70 & 0.84 & $7.93 \%$ \\
\hline & \multirow{2}{*}{$\begin{array}{l}\text { Middle } \\
\text { load }\end{array}$} & $3 \#$ & 2.56 & 0.21 & 2.77 & 2.96 & 0.86 & $7.58 \%$ \\
\hline & & $4 \#$ & 2.23 & 0.13 & 2.36 & 2.96 & 0.75 & $5.51 \%$ \\
\hline
\end{tabular}


It can be seen from the above table that the test efficiency coefficient of the bridge under various working conditions meets the requirement that the load efficiency coefficient is greater than 0.85 and less than 1.05 , so the test is effective. The measured deflection values of the mid-span section of the test bridge are all less than the theoretical calculation values, the deflection check coefficients of the main measuring points are all less than 1, the ratio of the maximum measured deflection to the calculated span is less than $1 / 600$ as stipulated in the code, and the structural stiffness meets the requirements of the code. The measured deflection of the mid-span section of the test bridge is similar to that of the theoretical calculation under the full load in the first and second working conditions, and no obvious sudden point is found, indicating that the lateral transmission force of the superstructure is normal.

\section{Conclusions}

1) Under the condition of test load, the relative residual values of all deflection and strain measuring points are not exceeded, indicating that the structure is in an elastic state and meets the requirements of bearing capacity;

2) The strain values generated by the strain measuring points of the arch ribs are relatively close under the conditions of medium and partial load of the bridge, indicating that the bridge has normal transverse transmission force and good transverse connection;

3) The reinforced concrete box ribbed arch bridge is not only beautiful, but also can save a lot of materials and space, and can reduce the project cost, which is worth popularating in the new arch bridge;

4) To sum up, the strength and stiffness of the superstructure of the bridge meet the design load (grade I-highway) and specification requirements, as well as the local traffic use demand.

\section{References}

1. Xu Y. (2013)Origin of Arch Bridges and Development of Stone Arch Bridges [J]. World Bridge, 41(3):85-92.

2. Tong Lin, PENG Yibin. Load Test research of Reinforced concrete Ribbed arch Bridge in service [J]. Highway and Motor Transport,2012(05):176180.

3. Yang Gen-jie. Analysis of mechanical property of sin-gle arch rib prestressed concrete beam arch combina-tion bridge[J]. Journal of Railway Engineering Soci-ety, 2017, 34(6):37-42.

4. Tong Qiuguo. Disease analysis and Reinforcement technology research of stone arch Bridges in service [D]. Changsha: Central South University of Forestry and Technology, 2011.

5. Ministry of Transport of the People's Republic of China,Specification for inspection and evaluation of load-bearing capacity of highway bridges: JTG/TJ21-2011 [S] 